\title{
POLÍTICAS PÚBLICAS E REESTRUTURACÃO DE REDES DE SOCIABILIDADES NA AGRICULTURA FAMILIAR
}

\author{
Celso Antonio Favero*
}

\begin{abstract}
O objetivo das pesquisas que dão origem a este trabalho é conhecer os deslocamentos produzidos na vida e na rotina dos agricultores familiares do semiárido do Nordeste do Brasil com a introdução das políticas de transferência condicionada de renda. Como o dinheiro dessas políticas, somado ao dinheiro de outras transferências, são apropriados, usados e representados nas famílias desses agricultores? Para responder essa pergunta, parte-se de quatro ideias: 1) atualmente, a territorialização do capital tende a buscar o seu equilíbrio na combinação entre territórios de produção de riquezas e territórios de transferência de renda; 2) o ingresso do dinheiro das transferências públicas promove deslocamentos com relação a posições e a disposições dos indivíduos nas famílias, e também das famílias nas redes locais de sociabilidade; 3) nas novas políticas para a agricultura familiar do semiárido, transita a ideia de desenvolvimento para o consumo; 4) o Estado tornou-se protagonista fundamental na produção desses deslocamentos.
\end{abstract}

PALAVRAS-CHAVE: território, semiárido, agricultura familiar, políticas públicas.

\section{INTRODUÇÃO}

Do valor de uso para o valor de troca, dos vínculos de reciprocidade para as relações reificadas e mediadas pelo dinheiro: ${ }^{1}$ com esses deslocamentos, são afetadas as estruturas da vida social e o próprio chão da vida. Revela-se, ao mesmo tempo, que a vida é, no seu viver cotidiano, espacializada e temporalizada, continuidade e deslocamento, tudo ao mesmo tempo. Milton Santos (1999), retoman-

* Doutor em Sociologia. Professor do Departamento de Ciências Humanas e do Programa de Pós-Graduação em Políticas Públicas, Gestão do Conhecimento e Desenvolvimento Regional no Campus I da Universidade do Estado da Bahia (UNEB).

Rua Silveira Martins, 2555, Cabula. Salvador-BA. CEP 41.150-000. celsoafavero@terra.com.br

1 "La dependencia mutua y generalizada de los individuos recíprocamente indiferentes constituye su nexo social. Este nexo social se expresa en el valor de cambio, y solo en este la actividad propia o el producto se transforma para cada individuo en una actividad o en un producto para el mismo. [...]. Su poder social, así como su nexo con la sociedad, lo lleva consigo en el bolsillo. [...]. En realidad, esta es una situación muy distinta de aquella en la cual el individuo, o el individuo natural o históricamente ampliado en la familia o en la tribu (y luego en la comunidad) se reproduce sobre bases directamente naturales, o en las que su actividad productiva y su participación en la producción está orientada hacia una determinada forma de trabajo y de producto, y su relación con los otros está determinada precisamente de ese modo.“ (Marx, 1986, p.84). do Marx, concebe a moderna produção capitalista dos espaços como uma produção baseada na tensão entre território e dinheiro, o que a coloca num determinado tempo, no qual o dinheiro assume caráter de regulador ou produtor da vida social, das riquezas e das misérias e, assim, dos sistemas de sociabilidade, dos territórios e da vida dos e nos territórios. Nesses mesmos processos, são forjadas novas formas de subordinação das tradicionais relações de reciprocidade e dos sistemas de reconhecimento recíproco à lógica trocadora e ao dinheiro, além de novos modos de reciprocidade e sistemas de reconhecimento recíproco.

O semiárido do Nordeste brasileiro e, especificamente, o Território de Identidade Bacia do Jacuípe (TIBJ), situa-se, atualmente, num desses momentos considerados seminais nos processos de formação de territórios, onde continuidades e deslocamentos se revelam com maior força. Duas razões nos levam a essa afirmação: 1) no conjunto do semiárido, o TIBJ é um desses espaços claramente marcados pela presença de índices relativamente significativos de pobreza e, assim, como um espaço onde a vida é mais lenta (Santos; Silveira, 
2001); 2) paradoxalmente, nos âmbitos da vida cotidiana no Território, nessa última década, vêm se tornando cada vez mais visível o encontro e desencontro entre um sistema social e econômico baseado em relações de reciprocidade e as novas formas pautadas por relações formais ou institucionalizadas, onde o mercado, o Estado e o dinheiro, nas suas diferentes formas, emergem como atores hegemônicos. O agricultor perde cada vez mais as rédeas sobre a sua vida. Assim, se, por um lado, o território social (o chão da vida e da rotina), politicamente (TIBJ) produzido com as escalas e as tensões que o estruturam, como que lhe foge das mãos para reaparecer como modo de vida regulado pelo Estado, por outro, e ao mesmo tempo, ele se torna laboratório onde são destruídos e produzidos atores, vínculos sociais, espaços sociais, instituições, objetos, representações, rotinas e o próprio chão da vida. É nesse chão, marcado pela tensão entre territórios sociais e políticos, campo de produção ou disputa de poder, que o agricultor produz a sua vida e redes de sociabilidades.

Recentemente, em estudo sobre a agricultura familiar, Eric Sabourin retomou a distinção feita por Eme e Laville entre "a economia mercantil capitalista (a troca), a economia pública (associada à redistribuição do Estado) e a economia gratuita, não-mercantil ou não monetária, assimilada ao princípio da reciprocidade” (Sabourin, 2009, p.258). Como desdobramento, ele recuperou o fio da discussão elaborada por Odile Castel, que distingue os motivos que estruturam cada um desses regimes de economia:

... o enriquecimento pessoal, por meio da maximização do lucro, motivo das atividades de troca capitalista; o compartilhamento, por meio da redistribuição praticada pelo Estado (serviços e auxílios públicos) ou por meio das atividades de proteção a bens e pessoas (seguros das associações e sociedades mutualistas); e a solidariedade econômica, realizada pela reciprocidade, motivo que fundamenta não só as atividades de ajuda mútua, como também as cooperativas e associações (Sabourin, 2009, p.259).

Castel e, em seguida, Sabourin recolocaram o problema da tensão entre as situações objetivas produzidas pelo movimento da economia e os interesses subjetivos dos sujeitos sociais. Ao ingressar na história da região, Sabourin mostra como os atores recombinam, de modos originais, essas três economias para produzir distintos sistemas de sociabilidade e distintas trajetórias. O semiárido, como espaço de vida tradicionalmente heterogêneo, reemerge como nova heterogeneidade.

Ao situarmos o problema nessa perspectiva, é interessante retomar um trabalho anterior no qual Sabourin afirmava que a criação dos "programas especiais de luta contra a seca” ${ }^{2}$ para o semiárido, que colocaram o Estado "nas trilhas das comunidades de base da Igreja Católica”, desencadeou um lento e irresistível processo de substituição dos vínculos sociais de reciprocidade por relações formais, baseadas em estruturas "sociotécnicas”, no “diálogo técnico" e no associativismo rural. Com o desenvolvimento desses programas, as redes comunitárias tradicionais de sociabilidade, fundadas em laços de reciprocidade e numa "economia gratuita”, se misturaram com redes de intercâmbio mercantil baseadas em relações sociotécnicas:

... a integração ao mercado e à sociedade global (administração, escola, igrejas, serviços técnicos) levaram a sociedade rural nordestina, os sítios e as comunidades a dotarem-se de novas estruturas de representação e de cooperação, sem, portanto, abandonar (pelo menos completamente) os valores e formas de organização camponesa fundadas pela reciprocidade (Sabourin, 1999, p.5). ${ }^{3}$

Neste trabalho, retomando resultados de longas investigações, ${ }^{4}$ pretende-se analisar as transformações atualmente produzidas pelo desenvol-

Sabourin refere-se, aqui, ao POLONORDESTE, criado em 1975, ao Projeto Nordeste, de 1982, e ao Programa de Apoio ao Pequeno Produtor Rural (PAPP), de 1985.

${ }^{3}$ Para o ingresso nos programas do Estado, a alternativa única para agricultores familiares era a do associativismo ou cooperativismo que, do ponto de vista do Estado, iria resolver o problema da precariedade jurídica da institucionalidade do "pequeno produtor" e daria segurança ao sistema financeiro emprestador; do ponto de vista do agricultor, o associativismo ou cooperativismo tornou-se mecanismo necessário para o acesso ao dinheiro do Estado. Rapidamente, essas organizačões proliferaram no semiárido. Em 2007, o TIBJ tinha 528 organizações associativas, cooperativas e sindicais rurais (MOC, 2007).

${ }^{4} \mathrm{O}$ investigação foi feita pelo "Grupo de Pesquisa Territórios, Hegemonias, Periferias e Ausências”, da Universidade do Estado da Bahia (UNEB). 
vimento de políticas públicas - referimo-nos, aqui, principalmente, às políticas públicas de transferência de dinheiro - nos modos de produzir e reproduzir a vida e nas formas de sociação e territorialização na agricultura familiar do semiárido do Nordeste e, mais especificamente, no TIBJ, na Bahia. ${ }^{5} \mathrm{O}$ ator principal com o qual se irá dialogar é o "beneficiário" do Programa Bolsa Família, um suposto "não-sujeito" público. O que se quer saber é como esses agricultores produzem as suas vidas, considerando as continuidades descontínuas entre os três regimes de economia, os três tipos de dinheiro, as formas de sociabilidade e, fundamentalmente, a sua relação com o Estado.

Quatro ideias estruturam o trabalho: 1) a que nos coloca na tensão entre território e dinheiro, ou na rota da produção dos territórios e do dinheiro, ou, ainda, da sua apropriação e do seu uso social; 2) a que no confronta com os dois modos de sociabilidade (reciprocidade e formal) e com os três regimes de economia (mercantil capitalista, pública e gratuita) e, portanto, com três tipos de dinheiro; 3 ) a que situa as relações entre diferentes territórios nos âmbitos das tensões e das escalas; 4 ) a que nos permite apreender os territórios, por um lado, no próprio processo de sua produção social e, por outro, como articulações de trajetos e deslocamentos de tempos e espaços sociais. Para fazer isso, é necessário, antes, situar o território nos contextos mais amplos das contradições capitalistas e traçar o cenário do que ele é hoje.

\section{UMA PORTA PARA O INGRESSO NO CAMPO DODEBATE}

Como apreender esses processos de desmanche e produção de vida, de sociabilidades e de territórios se, metodologicamente, optou-se por vêlos pela ótica do agricultor familiar e, mais precisamente, do "beneficiário" do Programa Bolsa Família (PBF)? O "herói do enredo" não é o Estado,

\footnotetext{
${ }^{5}$ O Território Bacia do Jacuípe entra, neste trabalho, de dois modos: como recorte geográfico ou campo onde se fez a pesquisa empírica e, secundariamente, como uma das expressões da ação política do Estado.
}

agente que se revela na sua obstinação em produzir territórios e "beneficiários" das suas ações e políticas; não é tampouco o capital, apesar de sua lógica (mercantil) tornar-se um dos motores dos processos formadores da vida; o herói é o agricultor familiar "beneficiário" do PBF, o segmento mais empobrecido da região; é o "homem simples" de Octavio Ianni (1975), esse sujeito

... comum, fragmentado, divorciado de si mesmo e de sua obra, mas obstinado no seu propósito de mudar a vida, de fazer História, ainda que pelos tortuosos caminhos de sua alienação e de seus desencontros, os difíceis caminhos cotidianos da vida (Martins, 2008, p.10).

O desafio que se coloca com essa escolha é o de como capturar este sujeito frequentemente silenciado, dito e predito pela negação por tantos outros que o dizem a partir de seus próprios tempos e espaços e de suas ciências (Martins, 1981). Para enfrentar esse desafio em termos teóricos, o trabalho foi estruturado utilizando-se, como fios condutores, além do conceito de agricultura familiar, os de território, semiárido e de políticas públicas. Como, no semiárido do Nordeste, principalmente no TIBJ, os agricultores familiares, no embate com o Estado e com os agentes do mercado, criam e recriam a si mesmos, produzem os seus territórios (o chão da vida) e os seus sistemas de sociabilidade? Essa é a questão.

De acordo com Giddens, o conceito de território pode ser estruturado com base nas noções de trajeto e deslocamento ("desencaixe"). Ao lançar mão desses conceitos entende-se: 1) que o ser humano é um ser situado num espaço-tempo e portador de um espaço-tempo; 2) que esse espaçotempo tem as suas fronteiras demarcadas pelas "trajetórias" dos indivíduos e dos grupos sociais que os constituem; 3) que internamente, e entre eles, os territórios são espaços-tempos de tensão que, frequentemente, se transformam em conflitos e, inclusive, provocam deslocamentos; 4) que as relações entre os diversos espaços-tempos podem dar origem a estruturas de escalas de territórios. Ou como afirma Giddens, nos territórios, as fronteiras tendem a "se acomodar sob as pressões e as 
oportunidades que decorrem de sua existência comum dos indivíduos e dos grupos sociais no espaço e tempo terrestre” (Giddens, 2003, p.143). As trajetórias se expressam, assim, pelo movimento dos agentes

... entre objetos cujas propriedades interagem com suas capacidades [...], ao mesmo tempo em que aqueles interagem uns com os outros [...]. As interações de indivíduos movendo-se no tempoespaço compõem 'feixes' [...] que se reúnem em 'estações' ou localizações espaço-temporais definidas, dentro de regiões circunscritas (2003, p.132).

Os trajetos (ações) - por entre objetos, intercalando estações - definem, portanto, os contornos frequentemente fluidos dos territórios individuais e sociais, escalares ou horizontais: até onde o ator se desloca, com que frequência, e movido por quê?

Os movimentos no espaço-tempo, permeados pela tensão, promovem, algumas vezes, deslocamentos, rompimentos de rotinas ou "desencaixes". Giddens distingue dois tipos de mecanismos de desencaixe "intrinsecamente envolvidos no desenvolvimento das instituições sociais modernas": 1) as "fichas simbólicas" ou os

... meios de intercâmbio que podem ser 'circulados' sem ter em vista as características específicas dos indivíduos ou grupos que lidam com eles em qualquer conjuntura particular. Vários tipos de fichas simbólicas podem ser distinguidos, tais como os meios de legitimação política (Giddens 1991, p.25)

Dentre as fichas simbólicas, o dinheiro seria, segundo Giddens, a mais poderosa, já que "possibilita a realização de transações entre agentes amplamente separados no tempo e no espaço" (1991, p.27) e, também, na medida em que reifica ou "dessocializa” as relações sociais. 2) Os "sistemas de peritos", ou "sistemas de excelência técnica ou competência profissional que organizam grandes áreas dos ambientes material e social em que vivemos hoje" e que se impõem, em grande medida, por meio de crenças que alicerçam vidas: a crença de que o que é dito pelos peritos é verda- deiro: os "sistemas peritos são mecanismos de desencaixe porque, em comum com as fichas simbólicas, eles removem as relações sociais das imediações do contexto" (p.31).

Os processos históricos de produção de territórios envolvem, pois, mais ou menos vastas pluralidades de atores, de tempos e de espaços dispostos, uns com relação aos outros, de forma tensa e, ao mesmo tempo, como diria Bourdieu, demarcados pelas posições sociais e disposições simbólicas de que são portadores e que conferem a cada um deles poderes desiguais na produção de territórios. Introduz-se, com isso, a ideia de escalas de territórios. Acselrad entende que a produção social de territórios só pode ser adequadamente reconhecida considerando-se as escalas dessa produção e que a atual reestruturação da geografia da produção, da circulação e da acumulação de capitais vem alterando as próprias "configurações espaciais e as escalas" territoriais, incluindo até mesmo as escalas das políticas públicas e "inaugurando novas e contraditórias formas de produção de espaço e de apropriação do meio ambiente.” (Acselrad, 2006, p.14). Com as transformações nos paradigmas produtivos e nos cenários sociopolíticos em escala internacional, os Estados deixaram de ser representados como fronteiras defensivas e se transformaram em plataformas ofensivas da economia mundial.

Historicamente, no final dos anos 1980, com o aprofundamento da crise em escala mundial, enquanto o capital elaborava teses baseadas nas ideias de flexibilidade regulatória e reajustamento estrutural, o Estado assimilava a ideia de "desenvolvimento sustentável”, que repercutiria na formulação das suas novas estratégias e na escala da distribuição da sua presença nos diversos territórios nacionais. Três grandes deslocamentos eram então produzidos: 1) a ideia de desenvolvimento foi inscrita num campo dominado pelas certezas: passou a ser concebido como matéria pura e, assim, como algo que estrutura e dá origem a uma causa universal, que teria na capacitação (a proliferação dos cursos de capacitação) o seu instrumento estratégico; o desenvolvimento foi concebi- 
do também em termos de desequilíbrio de consumo, o que requeria integrar os indivíduos como consumidores; 2) a ideia de desenvolvimento nacional foi substituída pela de desenvolvimento local; passava-se a mirar não mais a unidade ou coesão nacional, mas os segmentos, a diversidade e a competição entre territórios e atores, promovendo, inclusive, a emergência dos territórios nas suas distintas escalas; as assimetrias entre eles foram percebidas não mais com base em critérios de desigualdade, mas de diferença; 3) com base nessa concepção, foi ressaltada a distinção entre territórios empreendedores e territórios perdedores (Harvey, 2006). ${ }^{6}$ Do ponto de vista das políticas públicas, por exemplo, a incoerência, e não mais a coesão, se tornou uma dimensão central e funcional do Estado (Jobert, 2004, p.44). É no avanço dessas perspectivas que, mais recentemente, tomou vulto o debate brasileiro estruturado em torno de ideias como a da "abordagem territorial do desenvolvimento".

Éimportantelembrar ainda queamodernidade capitalista nos fez aprender que o reconhecimento ou negação de um território se mede pelo seu Produto Interno Bruto (PIB), pela riqueza que ele produz, pela capacidade e pela velocidade de produção dessa riqueza; que a produção de riquezas serve como o meio adequado para a classificação de um território entre os territórios, ou para situá-lo numa escala de reconhecimento e de negação. Hoje, ao contrário, num contexto marcado pela tensão entre territórios empreendedores e perdedores e pelo papel cada vez mais decisivo do Estado na produção de espaços, a riqueza de um território pode não ser mais identificada apenas como uma expressão do seu PIB. Por um lado, riqueza deixa de ser um termo unívoco e torna-se polissêmico: riqueza ambiental, cultural, econômica, educacional (e, para alguns, até da felicidade), do mesmo modo que o termo capital (humano, social e outros), de modo que o novo território pode ser reconhecido como lugar na produção de outras riquezas, não de PIB. Por outro lado, essa polissemia

${ }^{6} \mathrm{Na}$ Bahia, um dos estudos pioneiros utilizando essas noções foi realizado por Judith Tendler (1993). não é concebida, pelo menos nos discursos oficiais, em termos de fragmentação, de exclusão de sentidos, mas como uma nova complexidade. Inserida nesse contexto, a abordagem territorial do desenvolvimento produz uma espécie de deslocalização dos territórios para ressituá-los não mais numa escala elaborada em termos hierárquicos, desiguais, mas numa perspectiva que realça as identidades e diferenças entre eles, a sua capacidade empreendedora ou não, e as suas escalas (de poder), produzindo, com isso, um novo modelo de equilíbrio territorial. Esse é um novo modo como o capital estrutura a sua dinâmica de acumulação, considerando a questão do espaço.

Davezies, em estudo sobre os modos de produção dos espaços, sustenta que, hoje, na perspectiva do capital,

... o território não é apenas um fator de cresci-
mento (de riquezas); é também um suporte de
populações, uma comunidade humana para a
qual o desenvolvimento não se expressa em ter-
mos de 'produtividade dos fatores' ou de 'custos
de transações', mas apenas em termos de renda
dos domicílios, de emprego, de desemprego e de
pobreza [...]. Mais que o impulso da
competitividade, é o da atratividade que apare-
ce hoje como mais significativo para a saúde dos
nossos territórios. ${ }^{7}$ (2008, p.88).

Para o autor, o equilíbrio geográfico do sistema capitalista mundial se assenta cada vez mais na combinação en tre territórios de competitividade (produção de riquezas) e territórios de atratividade (apropriação de renda e de bens). A existência desses últimos estaria vinculada, essencialmente, à sua capacidade de captação de renda por meio de aposentadorias, do pagamento de agentes públicos (empregos públicos) e de prestações sociais, sem o estabelecimento de vínculo com a eficiência produtiva do território. Essa visão coloca em evidência, além dessa perspectiva de totalidade (unidade e distinção) e do seu caráter funcionalista de integração, a ideia de que o capital é capaz de criar distintos tipos de territórios, para distintas finalidades, todas elas subordinadas ao mesmo

7 Tradução livre do autor. 
modo de produção e de distribuição de valor.

David Harvey, ao estudar a "produção capitalista do espaço", recoloca o problema da produção de territórios no âmbito das contradições capitalistas e, portanto, das tensões sociais, políticas e econômicas. Ele concebe as atuais relações intra e interterritoriais como relações tensas, onde se contrapõem, além de classes e atores sociais, incluindo o Estado, territórios concebidos sob o prisma do "administrativismo" e do "empreendedorismo" (Harvey, 2006). O empreendedorismo produz, segundo o autor, uma alteração importante nos modos de produção, de apropriação e de representação social das riquezas e, assim, dos sistemas de sociabilidade. Assim, na visão do autor, ao identificar os sujeitos sociais e os territórios com base na sua capacidade ou eficácia competitiva, acaba-se por recolocá-los num campo dominado pelas certezas, fazendo-os emergirem como matéria destituída de caráter social, de contradições e de tensões.

Considerando essas abordagens, para este trabalho, entende-se: 1) que a produção de territórios se define pelos mesmos termos das demais produções histórico-sociais; 2) que o reconhecimento de processos de produção de territórios remete concretamente a conjuntos de relações (conflitivas e funcionais) entre atores; 3) que os atores que participam da produção de territórios se identificam nos processos a partir das posições objetivas (lugares nas estruturas, envolvendo escalas) e das disposições (os imaginários ou aparatos simbólicos, incluindo os projetos individuais e sociais) que carregam; 4) que os territórios resultantes desses processos, considerando as desigualdades e as dinâmicas de desqualificação ou anulação de atores, constituem, sempre, pluralidades de chãos, realidades complexas, múltiplas e desiguais, qualificadas e desqualificadas, que são, ao mesmo tempo, totalidades internamente tensas; 5 ) que, nas últimas décadas, considerando a agricultura familiar do semiárido, os diversos dinheiros assumiram o controle quase absoluto dos processos de produção de territórios, subordinando a eles os indivíduos e grupos sociais; tornaram-se o "meio"; 6) que, entre os dinheiros, o das transfe- rências públicas exerce o papel de agente maior dos processos de produção de territórios. Foi, enfim, fazendo esse percurso que nos aproximamos, mesmo que precariamente - já que precária é a nossa ciência, como precária é a vida, dos agricultores familiares no semiárido -, do "homem simples" e, também, de um ente pluriativo que combina, separando, três economias e relações sociais formais e de reciprocidade.

\section{AS ECONOMIAS NO TERRITÓRIO DE IDENTI- DADE BACIA DO JACUÍPE}

\section{Ingressando no Território}

O Território de Identidade Bacia do Jacuípe, ${ }^{8}$ no semiárido da Bahia, tem 220.000 habitantes. Em 2000, nas cidades-sede dos seus municípios, a população variava entre 2.203 (Gavião) e 23.320 (Ipirá) habitantes, o que caracteriza a região como essencialmente rural. ${ }^{9}$ Nesses municípios, exceto Pintadas, os recentes índices de evasão de habitantes são significativos: entre 1995 e 2006, o Território perdeu $33,23 \%$ dos seus habitantes, e o município de Riachão do Jacuípe perdeu 78\%. Em 2000, mais de $58 \%$ da população do Território residia no "meio rural" e, em alguns municípios, como Baixa Grande, ultrapassava os $65 \%$. Da população rural, mais de 90\% são agricultores familiares. Mas, entre 1991 e 2007, municípios como Capela do Alto Alegre, Gavião, Nova Fátima e São José do Jacuípe perderam mais de $50 \%$ da sua população rural. Com relação à população urbana, no entanto, há um leve crescimento na maioria

O TIBJ inclui os seguintes municípios: Baixa Grande, Mairi, Gavião, Capela do Alto Alegre, Ipirá, Nova Fátima, Pé de Serra, Pintadas, Riachão do Jacuípe, Quixabeira, São José do Jacuípe, Serra Preta, Várzea da Roça e Várzea do Poço.

${ }^{9}$ José Eli da Veiga (2004) propõe como modelo para o estabelecimento da distinção entre urbano do rural a combinacão de três variáveis: 1) o "grau de artificialização dos ecossistemas", que seria decorrente da ação da "espécie humana”, que, para a América Latina, somadas as áreas artificializadas e semiartificializadas, não ultrapassa os 38\%;

2) a densidade populacional, para o que ele indica alguns parâmetros, como o da OCDE para a União Europeia, onde se considera rural uma área com menos de 150 habitantes por $\mathrm{Km}^{2}$; 3) o grau de desenvolvimento rural. 
dos municípios, exceto em Gavião. Chama a atenção o caso de Serra Preta que, entre 1991 e 2000, viu sua população urbana crescer em $31,38 \%$, enquanto a população rural caía em mais de 30\%.

Segundo dados do Ministério do Desenvolvimento Social (MDS), em dezembro de 2008, o TIBJ detinha um dos maiores índices de pobreza do semiárido do Nordeste (78\% das famílias do Território eram consideradas pobres) e um dos maiores índices de "beneficiários" do PBF (74\% da população do território e $80 \%$ das famílias de agricultores familiares eram beneficiárias do programa). Entre 1991 e 2000, o IDH médio do Território manteve-se relativamente baixo, comparado com o estadual; ao mesmo tempo, a sua variação positiva foi superior à de municípios até então melhor situados no ranking estadual. ${ }^{10}$ Nesse período, em Várzea da Roça, por exemplo, o IDH médio cresceu de 0,461 para 0,591; em 2000, o município com IDH mais elevado era Várzea do Poço, com 0,665 (nesse ano, o IDH médio da Bahia era 0,688 e o brasileiro era 0,766). A taxa de analfabetismo no Território é de $32 \%$, a de abastecimento de água é de $35,1 \%$ e a de esgotamento sanitário urbano é de 30,6\%. Esses indícios, combinados com os de produção de riquezas e de transferência pública de dinheiro, permitem caracterizar o Território como região marcada pela precariedade.

Em 2007, de acordo com dados da Superintendência de Estudos Econômicos e Sociais da Bahia (SEI), o PIB do TIBJ foi de R\$ 664,25 milhões. Oito anos antes, em 1999, era de R \$ 251,97 milhões, o que significa que, nesse período, houve um crescimento de $263 \% .{ }^{11} \mathrm{O}$ município com maior volume de PIB e de maior crescimento relativo nesse período foi Ipirá, cujo sistema produtivo está estruturado principalmente com base na criação de bovinos e do Arranjo Produtivo Local

${ }^{10}$ Nos últimos anos, vem mudando o perfil da relação PIB-IDH em grande parte dos municípios do semiárido (SPE/SEPLANTEC, 2001).

${ }^{11}$ Nesse mesmo período, o crescimento do PIB brasileiro foi de $267 \%$, taxa pouco maior que a do Território. No entanto, se olharmos a partir dos dados per capita, perceberemos que a assimetria permanece grande: o PIB per capita brasileiro variou, nesse período (1999-2007), de $\mathrm{R} \$ 6.560,00$ para $\mathrm{R} \$ 13.515,00$ (o do Território atingia, em 2007, R\$3.019,00).
(APL) Artefatos de Couro (o PIB de Ipirá significa quase $1 / 3$ do PIB do Território).

Em 2007, o PIB per capita médio do Território foi de $\mathrm{R} \$ 3.019,00$ ( $\mathrm{R} \$ 251,60$ mensais). Nesse mesmo ano, na produção agropecuária, a agricultura familiar participava com $93 \%$ dos estabelecimentos, $54,6 \%$ da área e $66 \%$ do valor bruto. O valor médio anual bruto produzido por estabelecimento era, então, de R\$ 1.101,81 (valor médio mensal de R\$ 91,81). ${ }^{12}$ Além disso, considerando dados da SEI e SEAGRI, o valor bruto da produção agropecuária do TIBJ não mudou entre 1990 e 2008. O que mudou, nesse tempo, foi o número de famílias de agricultores, que diminuiu, aumentando, assim, a renda média por família. ${ }^{13}$

$\mathrm{Na}$ pesquisa que realizamos em 2008 no TIBJ,${ }^{14}$ considerando os principais produtos agropecuários, constatou-se que das 448 famílias entrevistadas, 421 (97,7\%) produziam feijão, 408 (94,7\%) produziam milho e 209 (48,5\%) produziam mandioca. Com relação aos destinos dessa produção, 96,7\% das famílias que produzem feijão, $97,3 \%$ das que produzem milho e $93,8 \%$ das que produzem mandioca destinam esses produtos para o autoconsumo. Na produção animal, segundo dados da pesquisa, a situação era idêntica: $47,2 \%$ das famílias produziam bovinos de leite e, dessas, $87,3 \%$ o produziam apenas para o autoconsumo;

${ }^{12}$ Considerando a produção agropecuária do território com base em séries históricas por produto, temos algumas surpresas: 1) a produção de 2008 é idêntica à de 1990; 2) em 2000, houve grande salto em termos de área plantada e de produto (no caso do feijão, a produção foi quase 6 vezes maior que a de 1995); em seguida, iniciou-se uma curva declinante atingindo, em 2007, patamar próximo ao de 1990; 3) a série histórica é marcada por grandes oscilaçóes para a maior parte dos produtos.

${ }^{13}$ De 1991 e 2007, a população rural do TIBJ passou de 197.427 para 125.546 habitantes, queda de $36,4 \%$. Assim, se o valor bruto produzido em 1990 é igual ao de 2007, o valor médio por família (cujo número diminuiu) aumentou. A migração pode repercutir, portanto, em crescimento do PIB per capita.

${ }^{14}$ Os seguintes dados revelam a precariedade da situação das 448 famílias entrevistadas: 48,4\% eram proprietários das suas terras, $13,6 \%$ tinham apenas a sua posse e as demais famílias eram parceiras, agregadas ou comodatárias. Com relação à quantidade de terras por estabelecimento, $53,4 \%$ tinham menos de 3,5 hectares e $88,9 \%$ tinham até 8,3 hectares. Com relação ao acesso à água, apenas $13,2 \%$ das famílias estavam integradas às redes de distribuição, 59,4\% tinham cisterna de bica ou tanque de cimento (água de chuvas) e 17,2\% recolhiam água para o consumo da família em açudes, barreiros ou represas. Além disso, 59,8\% das famílias consumiam água filtrada e $23,7 \%$ consumiam água coada. 
quase toda a produção de aves era destinada para o autoconsumo. Mas, segundo dados da mesma pesquisa, nenhuma dessas famílias produzia o suficiente para o consumo, daquele produto durante o ano.

A pluriatividade é uma marca da agricultura familiar do Território: alia-se, sob essa denominação, a produção no próprio estabelecimento, a “venda de diárias" e uma longa lista de atividades que poderíamos denominar “artesanais”, incluindo a coleta de produtos na natureza (licuri, mel silvestre de abelhas, palha para artesanatos, entre outros) e a própria produção de peças artesanais. Das 448 famílias entrevistadas, 361 (80\%) fazem o que chamam "trabalho assalariado" ou "venda de diárias"; 15 desse total, 31,9\% dedicam mais de 180 dias no ano para esse tipo de atividade. ${ }^{16}$ A precariedade está presente em todas essas modalidades de trabalho: no estabelecimento (tecnologias, dependência dos ciclos naturais e das suas variações), no trabalho assalariado (preços, vínculos, condições) e nos trabalhos de coleta ${ }^{17}$ e produção artesanal.

Como forma de incentivo à produção agropecuária familiar no Território, o Programa Nacional de Fortalecimento da Agricultura Familiar (PRONAF) aparece como o instrumento mais importante. ${ }^{18}$ Do Governo do Estado, o principal Programa de Desenvolvimento que afeta mais fortemente a agricultura familiar do Território é o PRODUZIR. ${ }^{19}$ No TIBJ, em 1997, dois municípios

15 Em algumas comunidades rurais, ouvimos - entre risos - a designação "dia de macaco" para a venda de diárias. O termo apareceu em reunião (roda de conversa) em uma comunidade rural com predomínio de população negra (pronunciado por negros); ao que parece, é um termo de uso antigo, portador de caráter discriminatório e racista, mas assimilado pela cultura local.

${ }^{16}$ Para essas famílias, o trabalho no estabelecimento ocupa menos da metade do tempo/ano.

${ }^{17}$ No coleta de licuri, realizada em geral por mulheres e crianças, o preço pago gira em torno de $\mathrm{R} \$ 2,00$ por quilo, que é a produção média diária de uma pessoa.

${ }^{18}$ Em 1994, Itamar Franco criou o Programa de Valorização da Pequena Produção Rural (PROVAP); em 1996 passou a se denominar Programa Nacional de Fortalecimento da Agricultura Familiar (PRONAF). Nos primeiros anos após a sua criação, ele ficou concentrado no Sul do país.

${ }^{19} \mathrm{Na}$ versão atual (Produzir III2), são desenvolvidos 47 projetos, atingindo 7.315 famílias e envolvendo $\mathrm{R} \$$ 5.483.663,00. Desses, 24 são destinados para a construção de cisternas individuais. Na ordem relativa de importância, nas duas versões do Projeto, o segundo que- do território tiveram contratos de PRONAF; em 2001, foram incluídos todos os demais. Desde então, variam anualmente o número de contratos, o montante de recursos alocados e a média de recursos por contrato. O valor total de recursos alocados no Território é pouco significativo: em 2008, por exemplo, foram injetados em torno de R\$ 8.316.000,00 para 2.715 contratos (média de $\mathrm{R} \$ 3.063,00$ por contrato), atingindo menos de $10 \%$ dos estabelecimentos familiares do território. Considerando o número de contratos e a média de valor alocado por contrato, pelo menos neste Território, o PRONAF não se constitui como política potencializadora do crescimento econômico ou da produção de riquezas.

\section{As transferências públicas de valor para a pro- dução de territórios}

Se a agricultura familiar do território é marcada pela precariedade, se os recursos alocados em termos de financiamento e de outros tipos de repasses de recursos pelo Estado são pouco significativos, e se a riqueza ali produzida é relativamente pouco representativa, inclusive na composição do orçamento familiar, paradoxalmente, o mesmo não ocorre com relação ao IDH. Resultados de estudos sobre a distribuição espacial da pobreza na Bahia sugerem que, nas últimas décadas, ela tende a se concentrar em áreas metropolitanas (SEI, 2008); outros estudos indicam que a dinâmica de crescimento econômico tende a separar-se da dinâmica de desenvolvimento social (SPE/ SEPLANTEC, 2001). Entende-se, assim, que: 1) está ocorrendo, em determinadas regiões da Bahia, um deslocamento das economias gratuita e mercantil capitalista para a economia pública; 2) os resultados do crescimento econômico de regiões caracterizadas como de crescimento mais vigoroso é, em parte, capturado por regiões de menor cres-

\footnotetext{
sito que mais recebeu financiamento foi a construção de sanitários residenciais. Mas, considerando o conjun to das ações, fica evidente que o impacto do Produzir na potencialização da produção agropecuária do território é
} pouco significativa. 
cimento; 3) que as políticas redistributivas do Estado exercem uma função muito importante na obtenção de um novo equilíbrio entre as regiões.

O TIBJ é, claramente, um desses territórios cuja vida e dinâmica depende de transferências públicas ou de uma economia pública, apesar de não ser um Território de "atratividade" do ponto de vista das populações; atrai renda. Neste trabalho, não se pretende fazer um estudo exaustivo envolvendo todos os programas e políticas de transferências públicas de dinheiro para o Território. Isso não significa desconhecer os programas e políticas não-contemplados e, menos ainda, o possível impacto deles no Território. O que se pretende é apenas abrir uma porta para o estudo das novas formas de produção econômica, social e política de territórios. Consideram-se, em função disso, apenas três programas, que são, sem dúvida, os de maior impacto nesse campo: as transferências constitucionais para os municípios, as transferências previdenciárias na forma de aposentadorias e as transferências assistenciais através do Programa Bolsa Família. Mas o que interessa desses programas são os montantes de recursos, comparados com os valores relativos à produção de riquezas. A finalidade é obter uma aproximação com relação aos principais indutores na produção de territórios.

\section{As transferências constitucionais ou municipais}

A maior fonte de transferências públicas de dinheiro para o Território é a das Transferências Constitucionais para os municípios. Em 2007, a receita total dos municípios do TIBJ atingiu $\mathrm{R} \$$ 174.760.237,36; nesse mesmo ano, as receitas de transferências somaram $R$ \$ 162.231.391,62, o que significa 92,6\% do total das receitas. Sete anos antes, em 2000, as receitas totais somavam $\mathrm{R} \$$ 74.999.479,17 e as receitas de transferências eram de $\mathrm{R} \$ 72.800 .929,96$, pouco menos de 97,3\% de todas as receitas, índice ligeiramente superior ao de 2004, que foi de $96,6 \%$.

Verifica-se, portanto, primeiro, que há um muito lento crescimento relativo das receitas pró- prias dos municípios; segundo, que, nesses sete anos, as receitas de transferência cresceram em 125\%. É importante ressaltar, ainda, que, com relação ao destino dessas receitas, o volume maior vai para as folhas de pagamento e despesas correntes, o que transforma os municípios nos maiores contratadores de mão de obra do território e, também, em reféns das instâncias estadual e federal.

\section{As transferências previdenciárias na forma de aposentadorias}

De acordo com dados do "Informe de Previdência Social" de 2001, naquele ano, os recursos transferidos em forma de aposentadoria beneficiavam aproximadamente $47 \%$ da população do semiárido do Nordeste e 78,5\% da sua população rural, transformando a região numa

... verdadeira 'economia sem produção' [...], uma vez que os beneficiários representam uma transferência direta de renda sem contrapartida de 'prestação de serviços produtivos' [...]. Em outras palavras, os beneficiários da Previdência não produzem, mas se apropriam de uma parte da renda nacional. E a renda desta 'economia sem produção’ chega a ser superior àquela gerada pela agropecuária tradicional, não podendo ser subestimada (Sandi; Heringer, 2001).

No TIBJ, em 2007, o número de benefícios previdenciários era de quase 42.000 (considerando-se a média de um benefício por família, em torno de $84 \%$ das famílias seriam beneficiárias); do total dos beneficiários, $83 \%$ eram agricultores. Os recursos transferidos para o conjunto desses beneficiários, nesse ano, no Território, somaram $\mathrm{R} \$$ 190.677.267,00 (BRASIL, 2010), ou seja, mais que o total das próprias transferências municipais. Nesse ano, cada beneficiário recebeu, em média, $\mathrm{R} \$ 4.540,00$, ou seja, mais de R\$ 378,00 por mês. ${ }^{20}$ Considerando que, nesse ano, em torno de 50.000 famílias residiam no Território, a média anual de recursos transferidos para cada família era de $\mathrm{R} \$$ $3.813,00$, ou $R \$ 317,80$ reais por mês. Na agricul${ }^{20}$ Naquele ano, o Salário Mínimo era de R\$ 380,00. 
tura familiar, o que se percebe, pelo menos empiricamente, é que, com as aposentadorias, vem crescendo a importância dos idosos nas famílias, que acabam até mesmo se organizando em torno deles. Esse recurso, embora constitua um sistema próprio de apropriação e uso, se cruza com outros dinheiros, como o do PBF.

\section{O Programa de Assistência Social Bolsa Família}

Outra importante fonte de receitas por via de transferências é o PBF. No TIBJ, em janeiro de 2008, o PBF tinha 35.698 famílias beneficiárias, atingindo em torno de $74 \%$ das famílias do território. Atualmente, $80 \%$ das famílias de agricultores familiares do território são beneficiários do PBF. O montante de recursos transferido mensalmente para o Território, em 2008, foi de R \$ 3.170.322,00, totalizando $\mathrm{R} \$ 38.043 .864,00$. A média mensal de recursos por família beneficiada era de R $\$ 88,80$, ou, aproximadamente, $R \$ 1.065,00$ por ano, quantia pouco inferior ao valor médio mensal produzido na agricultura familiar do Território, que era de R $\$ 91,81$.

\section{Uma quase síntese}

As Transferências Constitucionais Municipais, as aposentadorias e o PBF têm algo em comum: são institutos de transferência pública de dinheiro; a sua presença afeta profundamente, direta (caso das aposentadorias e do PBF) ou indiretamente (Transferências Constitucionais Municipais), a renda da população, repercutindo na dinâmica do mercado local e na própria vida cotidiana da população. $\mathrm{O}$ volume de recursos dessas transferências, comparado com o do PIB do Território, é significativo: em 2007, as transferências desses três instrumentos (não são contabilizadas, aqui, as transferências feitas com base em diversos outros programas), somadas, ultrapassaram os $\mathrm{R} \$$ 403.480.000,00, enquanto o PIB do Território era de R\$664.250.000,00. Embora não revelem tudo, esses números são importantes para se entender a configuração atual do TIBJ e, essencialmente, a relação entre as três economias e o significado disso na vida cotidiana das famílias de agricultores: 1) em 2007, considerando os três programas, as transferências equivaliam a 60,7\% do PIB do Território; 2) nesse ano, o PIB per capita foi de R $\$ 3.019,00$ (R\$ 251,60 por mês); o valor médio anual bruto produzido por estabelecimento agropecuário foi de $\mathrm{R} \$ 1.101,81$ (média de $\mathrm{R} \$ 91,81$ por mês); o valor médio anual de recursos transferidos na forma PBF por família foi de $\mathrm{R} \$ 1.065,00$ (média de $\mathrm{R} \$ \mathbf{8 8 , 8 0}$ mensais). Esses dados indicam a importância da economia pública no Território e a precariedade do sistema produtivo (economias gratuita e mercantil).

\section{DOS USOS DOS DINHEIROS PÚBLICOS E PRODUÇÃO DE TERRITÓRIOS}

O ingresso do dinheiro público na vida do agricultor familiar do semiárido tem uma história que não é longa: POLONORDESTE, Projeto Nordeste, PAPP, Projetos Padre Cícero e São Vicente, Sertão Forte, Faz Cidadão, Cabra Forte, Produzir... Esses dinheiros desencadearam um processo que perturbou o cotidiano das famílias. Antes, o Território controlava o dinheiro, como diria Milton Santos. Além disso, o dinheiro que começou a entrar é dinheiro do "governo" e do "banco", não dinheiro de venda de força de trabalho (diárias) ou de produtos. Para obtê-lo, nos anos de 1970-1990, o agricultor precisou associar-se e aprender o caminho do banco. ${ }^{21}$ No início, o dinheiro ia para a "associação" e não para a família; quase sempre "gratuito" (a fundo perdido), destinava-se a potencializar estruturas produtivas e o "alívio da pobreza". O território atingido era o território produtor de riquezas. Mais tarde, chegou o PRONAF, tendo como beneficiários, em geral, as famílias de agricultores que se mostravam empreendedoras. Não era mais

${ }^{21}$ Ver: Favero, Celso Antonio. Segundo o autor, no início dos anos 1990, diferentemente do que ocorre hoje, o financiamento da agricultura familiar tinha como captadores sujeitos coletivos ou associativos; a unidade captadora de financiamentos na agropecuária empresarial era o indivíduo proprietário. 
um dinheiro "gratuito”, mas portador de juros, produtor de dívidas; o dinheiro "gratuito" continuou chegando, mas em menor volume.

Com esses programas, o agricultor familiar ingressou no campo do Estado e do Banco, tornou-se visível, primeiro, como ser coletivo, de um coletivo formal; em seguida, com o PRONAF, a unidade recebedora passou a ser a família. O mais importante nisso é que, ao ingressarem no circuito do Estado/Banco, as famílias dos agricultores alongaram os seus trajetos, se endividaram, produziram novas redes de sociabilidade e campos de tensões, permeando a reciprocidade com a troca.

Com a promulgação da Constituição de 1988, e, principalmente, após 1991, com a nova regulamentação da previdência social rural, ganhou importância um instrumento que contribuiria mais fortemente para o "alívio da pobreza" rural no semiárido: as aposentadorias, primeiro, para um dos membros da família, normalmente o homem, em seguida, também para o cônjuge. Mas, apesar do peso relativo desse instituto, foi com o PBF que se introduziu uma nova modalidade de presença do Estado na relação com a pobreza no semiárido. O PBF é o primeiro grande programa que não têm vínculos com o trabalho (pelo contrário, quem trabalha-mediante contrato formal-está excluído do programa), mas foca no consumo.

A agricultura familiar do Território situa-se, portanto, nesse cenário onde se combinam diversos programas de políticas públicas de transferência de dinheiro e diferentes modos de produção ou apropriação de riqueza e renda. A pesquisa de campo realizada no Território colocou em evidência essa complexidade e, mais que isso, que nãoé mais possível entender os deslocamentos que vêm sendo atualmente produzidos no âmbito das sociabilidades e das territorializações na região sem considerar essas novas tensões. Nos itens anteriores deste trabalho, com base em dados secundários e com um olhar construído a partir dos sistemas de políticas, procurou-se entender as transformações que estão se operando no TIBJ; neste, faz-se um deslocamento com a finalidade de perceber como os agricultores familiares do Território se apropriam dos recursos das transferências, usam e significam esses recursos na produção do seu cotidiano e, assim, dos seus territórios de vida.

Com essa finalidade, o item foi organizado em duas partes. Na primeira, tenta-se entender as transformações que foram produzidas nos últimos anos nos espaços e trajetórias no âmbito das rotinas do cotidiano das famílias, centrando o olhar na casa e ao redor dela. Na segunda, procura-se conhecer as mudanças que ocorrem nos espaços e trajetórias que estruturam as redes de sociabilidades no âmbito das comunidades, dos municípios e da região. Recupera-se, para isso, primeiro, a ideia da tensão entre os três regimes de economia e os distintos regimes de sociabilidade na produção do território; segundo, a ideia da diversidade e da tensão no interior dos territórios sociais e no âmbito das escalas de territórios; terceiro, que as mudanças nos sistemas de sociabilidade significam, essencialmente, o desmanche e a produção de sujeitos sociais, objetos, sistemas de representação e campos de ações sociais.

\section{A (re)estruturação dos territórios domésticos ou das rotinas do cotidiano}

Três tipos importantes de deslocamento ocorrem nos espaços das rotinas diárias, em que o personagem central é a família: a reorganização da casa, a reestruturação dos sistemas e hábitos, principalmente dos hábitos alimentares, e a reestruturação dos lugares ou papéis dos indivíduos nesses espaços. Os três âmbitos não são concorrentes, mas combinados. Para essas mudanças, há a concorrência de inúmeros fatores: desde os movimentos de populações até as transformações no âmbito institucional e as infraestruturas disponibilizadas. Mas a criação ou disseminação de programas públicos de transferência de renda, como o PBF, e de bens, como o programa luz para todos e o de cisternas caseiras, contribuíram significativamente para essas mudanças. Eles disponibilizam infraestruturas básicas, potencializam a monetarização das relações sociais e, no caso do 
PBF, em virtude das "condicionalidades", promove deslocamentos nos trajetos dos distintos membros da casa. Esse programa tem, além disso, um efeito simbólico importante:é uma concessão para os pobres.

Em termos de infraestrutura, dos 448 domicílios pesquisados, $74,3 \%$ têm luz elétrica, $20,5 \%$ usam luz de querosene, $73,3 \%$ possuem aparelhos de televisão, $46 \%$ possuem geladeira, $33 \%$ possuem celular, 59,4\% possuem cisternas caseiras e 13,2\% têm acesso à rede geral de abastecimento de água. A luz elétrica e o acesso à água são fatores estruturantes do novo modo de organizar a casa e a vida. De acordo com depoimentos obtidos nas "rodas de conversas", a maior parte desses bens foi adquirida mediante pagamento em prestações, para o que contribuiu o fato de estarem recebendo algum tipo de dinheiro de transferência pública. A combinação de eletricidade, acesso à água potável e dinheiro de transferências públicas é, portanto, fator determinante para os deslocamentos no universo dos objetos, das ações e da organização da vida.

Na região, tradicionalmente, os sistemas de objetos no interior das casas foram organizados considerando duas "estações" principais: a cozinha e a sala. A cozinha - onde se ficava por longos períodos durante o dia - estava virada para o fogão (a lenha), objeto localmente produzido e símbolo do sistema reprodutivo das famílias. A água era, em geral, buscada longe. A nova cozinha, ao contrário, é descentrada, combinando o fogão a lenha com o fogão a gás (presente nas casas, mas pouco usado em virtude do preço do gás), as prateleiras onde se guardam os alimentos misturamse com a geladeira, os pratos e as panelas velhas estão juntos com utensílios novos, assim como as comidas tradicionais combinam com as exóticas. Atrás da cozinha, está a cisterna que capta águas de chuvas, o que repercute na diminuição do trabalho da mulher, Mas, a cozinha continua sendo território da mulher, a responsável maior pela reprodução da família.

A sala tradicional, por sua vez, era essencialmente voltada para fora, tinha a porta aberta para frente da casa. Nela, frequentemente, encontravase um pequeno "altar" com velas e estátuas dos santos da família, quadros ou recortes de revistas colados nas paredes e alguns tamboretes, bancos ou cadeiras onde as visitas sentavam. Era o lugar onde se recebiam vizinhos, parentes e, principalmente, pessoas estranhas. A nova sala - da luz elétrica - olha para o televisor. As cadeiras e os bancos estão virados para o televisor e não para o altar (meio desaparecido), o que torna a sala a estação mais frequentada da nova casa. A porta da sala, que se abre para frente, é um lugar de ficar. Mas, em grande medida, as conversas com vizinhos vêm sendo substituídas pelo "olhar televisão". A vida social fora de casa se subordina às demandas da televisão. Na nova casa, parecida com uma casa da cidade, a família tende a reorganizar-se a partir dos novos objetos, produzindo novos trajetos e novas redes de relações.

Uma das mudanças mais visíveis nesse quadro refere-se aos cardápios e hábitos alimentares: reorganizam-se os sistemas de produção, de classificação, de consumo e de representação dos alimentos. Tornou-se frequente, em conversas, a queixa das mães com relação à resistência de crianças e adolescentes em consumir alimentos tradicionais da região. A enunciação do nome de alguns desses alimentos em rodas de conversas tais como "bengo" (animal parecido com o sariguê), "fufu" (milho torrado e amassado no pilão) e "rabo seco" (mistura de farinha, pimenta e sal) - era recebida com risos e mistos de constrangimento e vergonha. O constrangimento aparecia, também, ao comparar alimentos produzidos em casa com alimentos comprados nos mercados. A menção de nomes de alimentos oriundos da cidade é feita sem travas, o que sugere que está em processo uma dinâmica de reclassificação dos alimentos e de reorganização dos cardápios domésticos, repercutindo em mudanças de rotinas, trajetos e modos de estruturação das tarefas dos membros da casa.

O terceiro tipo de mudanças no âmbito doméstico diz respeito às posições e aos papéis dos indivíduos no arranjo da casa. A contribuição do PBF, combinada com a eletrificação rural e a cons- 
trução de cisternas, parece mais evidente. A mulher é quase sempre a beneficiária direta do PBF, que reorganiza a sua vida e as suas relações com os filhos e o marido: é ela quem recebe o dinheiro (em muitos casos, ela é responsável pela apropriação do maior volume de dinheiro da casa); se torna mais ativa nas decisões sobre os sistemas de uso do dinheiro; assume responsabilidades com relação aos provimentos nos campos da saúde e da educação dos filhos (condicionalidades do PBF); pelo fato de receber o dinheiro e de retirá-lo do banco, acaba produzindo novas redes sociais e em novos circuitos comerciais. A mulher se torna mais visível na casa e fora dela, dando origem, inclusive, a novos campos de tensões e conflitos. Se o papel e o lugar da mulher sofreram grandes deslocamentos, o mesmo ocorreu com relação às crianças e ao homem. Enquanto as crianças vão para a escola, geralmente na cidade, com transporte coletivo, o marido está procurando vender diárias e pouco fica em casa.

\section{A (re)estruturação dos territórios amplos (tra- jetos longos)}

Com relação aos deslocamentos produzidos nos espaços amplos, igualmente, neste trabalho, são considerados: 1) os que reorganizam o mundo dos objetos no espaço amplo, 2) os que reestruturam o universo do associativismo ou cooperativismo e da política; 3) os trajetos dos membros das famílias dos agricultores familiares que foram induzidos por esses programas e que os conduzem, por exemplo, para a cidade. São âmbitos que não se separam nem das mudanças produzidas nos espaços domésticos e, menos ainda, entre esses três âmbitos. Além disso, essas mudanças ocorrem em ritmos e formas distintas nas sub-regiões do TIBJ e, também, na relação entre uma família e outra. Através delas não se cria nenhuma homogeneidade social, que também não havia antes; são produzidos novos campos permeados de novas tensões.

A "cidade" está ficando cada vez mais próxima da "roça". Nos últimos dez anos, $36,4 \%$ das famílias entrevistadas mudaram de domicílio, transferindo-se principalmente para vilas e sedes de municípios no próprio território. Dois fatores contribuíram para esses deslocamentos, segundo relatam os agricultores: a insegurança (medo de assaltos e de "ladroagem") e a procura de acesso a "oportunidades de trabalho". O alongamento dos trajetos (escola, postos de saúde, casas lotéricas, bancos, feiras e mercados) ou a aproximação da cidade tem o seu preço: a melhoria das condições das estradas, a substituição do animal pelo ônibus e a motocicleta, além da disponibilidade de transporte "coletivo", em geral, o transporte escolar e o transporte clandestino. Em 12,9\% das famílias entrevistadas, a motocicleta tornou-se o principal meio para o deslocamento para a cidade (apenas $0,9 \%$ das famílias afirmam que utilizam o lombo do animal).

No aspecto "organização social", as mudanças não foram menos significativas. No Território, quando do aparecimento do PBF, os agricultores familiares já contavam com uma grande rede de Sindicatos de Trabalhadores Rurais e de Associações Comunitárias ou de Produção. Essas organizações (que eram pautadas pela ideia de que a produção de territórios se faz via produção de riquezas) introduziram os agricultores familiares no campo da economia da troca mercantil e fomentaram a emergência de um modelo de assistência social (saúde, previdência, alívio da pobreza...) que requeria, como condição necessária, o estabelecimento desses vínculos sociais laterais e formais. Todas essas organizações se mantêm, ainda hoje, fiéis às tradições que as constituíram: representam o acesso a uma institucionalidade que reorganizou o cotidiano das famílias, alongou os trajetos dos seus membros, principalmente do homem, e expandiu as fronteiras dos territórios. Entretanto, ao mesmo tempo, elas não extinguiram a economia gratuita $\mathrm{e}$ as tradicionais relações de reciprocidade familiais e de vizinhança que tinham na mulher e nas crianças os atores mais importantes.

OPBF induza umnovomodelo organizacional e inaugura um novo sistema de relações, onde, pelo menos no aspecto jurídico, o vínculo reque- 
rido passa a ser essencialmente de caráter vertical (indivíduo e família com o Estado). Com base nesse novo modelo, são produzidos inúmeros deslocamentos na agricultura familiar, tais como: 1) com relação ao título de "reconhecimento" no Território - os agricultores familiares são cada vez menos socialmente "reconhecidos" como "agricultores" e cada vez mais como "beneficiários" do PBF; contribui para esse reconhecimento o fato de a maior parte das famílias do Território serem beneficiárias, tornando-se o não-beneficiário um estranho; 2) com relação às organizações associativas e sindicais (laços laterais) - essas organizações tornaram-se lugares aonde se vai unicamente para solicitar do Estado determinados serviços de assistência; 3) com relação ao trabalho ou produção e ao dinheiro ou renda - na era do PBF, o que define a representação da vida no Território é cada vez mais o dinheiro ou renda, que serve para o alívio do consumo, deixando o trabalho ou produção em segundo plano.

$\mathrm{O} P B F$ contribui significativamente para a produção dos "coletivos de destino":

... essa designação quer dizer que esse agregado não constitui uma coletividade organizada, não ocupa posições homogêneas na divisão social do trabalho, mas constitui-se socialmente como categoria de assistência pública. (Ivo, 2008, p.201)

Mas, contraditoriamente, esses coletivos de destino vêm se transformando em "coletivos votantes", sem perder o seu caráter de agregado social. Embora o voto se expresse, no âmbito do consumo, como ato individual, a sua produção supõe esses coletivos de destino. Esse é um dos principais deslocamentos que vem ocorrendo no Território com a introdução do PBF. A produção de um coletivo de beneficiários dá origem a enormes "coletivos de votantes" desorganizados, medrosos, inseguros, mas confiantes. Não confiantes "no governo", menos ainda "no Estado". Confiantes naquele que seria o fautor do benefício, o governo federal, personalizado no presidente. O agente político local, vinculado à prefeitura, é, para o beneficiário do PBF, aquele que causa medo, pois pode "tirar" o Bolsa Família. O governo federal dá; a prefeitura pode tirar. Reestrutura-se, assim, a própria estrutura do fazer tradicional da política, que tinha nos "políticos" locais os agentes de "confiança": o que era distante se torna próximo (confiança), o que era próximo se distancia (medo). ${ }^{22}$

Inseridos numa realidade, os "beneficiários" do PBF estão reinventando os seus sistemas de sociabilidade e os seus trajetos. Funda-se um novo "precariado", adequado para esses novos tempos. Nesse contexto, tão importante quanto a tensão entre previsibilidade (confiança) eimprevisibilidade (medo) é o fato de que o PBF tornou-se benefício massivo, envolvendo mais de 70\% das famílias do Território e contribuindo visivelmente para a produção de novos sistemas de relações econômicas, sociais e políticas: 1) o "homem simples" agora tem dinheiro e em volume suficientemente significativo para mexer nas dinâmicas dos mercados locais; 2) ao apropriaremse do dinheiro, os beneficiários do PBF, além de comprar comida, adquirem outros objetos, reorganizando, desse modo, os sistemas de objetos, e, consequentemente, o modo de organizar a vida e as suas ações e representações, inclusive as próprias representações sobre o acesso, a apropriação e o uso de dinheiro; 3) com o acesso ao dinheiro do PBF, é provável que esteja em marcha outro tipo de mudanças nas representações do "homem simples" do Território: o dinheiro toma o lugar da produção para o autoconsumo e, assim, da terra. A produção no estabelecimentoé descrita como risco e, frequentemente, como aposta inconsequente: a natureza mudou, as terras perderam suas qualidades, as tecnologias disponíveis tornaram-se inadequadas! Ao serem indagados se preferem o "emprego" ao trabalho no estabelecimento, optam pelo emprego: dá mais segurança e, com ele, pode-se comprar o que é necessário.

\section{CONSIDERAÇÕES FINAIS}

Neste trabalho, procurou-se analisar as dinâmicas de produção de sociabilidades e territóri-

${ }^{22}$ A equipe de pesquisa esteve no Território, em comunidades rurais, por dias seguidos durante o período eleitoral (eleições para presidente e governador). 
os num contexto onde são marcantes as tensões e as continuidades descontínuas entre relações sociais de reciprocidade e institucionalizadas, por um lado, e entre as economias gratuita, mercantil capitalista e pública, por outro. O cenário da pesquisa, marcado pela crescente tensão entre o dinheiro que reifica quase tudo e as dinâmicas de produção gratuita, é um Território do semiárido e, nele, o olhar se concentrou em famílias de agricultores "beneficiárias" do PBF.

Para a realização da pesquisa considerouse, primeiramente, que a chave para a resposta das questões que estruturam o trabalho faz referência aos modos como se entendem as dinâmicas de apropriação e uso (assimilação), pelos agricultores familiares, dos símbolos emanados do Estado e do capital, particularmente o símbolo dinheiro. Considerou-se, em segundo lugar, que é necessário ainda avançar muito na investigação sobre a configuração de cada uma das três economias do território e das tensões entre elas, e das tensões entre os vínculos de reciprocidade e institucionais. Em terceiro lugar, entendeu-se que, para realizar uma abordagem profícua desses problemas, a apropriação dos conceitos de trajeto (no espaço-tempo), deslocamento (no espaço-tempo) e escalas (de territórios) pode abrir caminhos importantes para o estudo dos processos sociais de produção de territórios. Finalmente, a partir deste trabalho, considerase que é muito importante recolocar os processos de produção de territórios e de sociabilidades no âmbito das relações sociais e, portanto, num campo marcado pelas contradições e, consequentemente, pelas tensões e conflitos entre os diversos atores sociais e políticos. Os deslocamentos dão origem a novos campos, marcados por contradições, conflitos e tensões. Essas são, provavelmente, as principais contribuições deste trabalho.

Quanto aos resultados, o estudo aponta para um amplo conjunto de deslocamentos que vem sendo produzido nas duas últimas décadas, nos âmbitos da produção de riquezas e de renda e das relações entre as três economias, e no plano das relações de sociabilidade e da territorialização, que afetam, de modo significativo, o cotidiano das fa- mílias de agricultores familiares da Bacia do Jacuípe. Essas mudanças podem ser articuladas em torno de três eixos que, no cotidiano das famílias, constituem dimensões de uma mesma complexidade e de um mesmo processo.

No âmbito da economia: 1) a nova economia do Território constitui-se a partir da combinação ou oposição entre as economias mercantil capitalista, pública e gratuita; 2) no plano da classificação segundo o grau de contribuição para a produção da subsistência das famílias na agricultura familiar do Território, a economia gratuita vem perdendo o lugar para a economia pública; 3) o campo a partir do qual se forma a identidade dos agricultores familiares é paulatinamente deslocada do âmbito da produção para o do consumo; 4) o dinheiro ganha cada vez maior autonomia e se torna o agente central nos processo de produção de relações sociais e de territórios; 5) o território da economia ganha novos contornos, novas escalas e é perpassado por novas contradições.

No âmbito da política: 1) o TIBJ - como escala de territórios - não expressa quase nenhuma densidade, é algo muito estranho para os agricultores familiares, exceto para algumas poucas das suas lideranças; 2) os programas de políticas públicas, principalmente os de transferência pública de recursos, em virtude dos modos como são formulados, induzem deslocamentos significativos com relação às posições ou disposições dos diversos atores e induzem a produção de novos territórios; 3) do ponto de vista das famílias dos agricultores familiares "beneficiárias" do PBF, o Governo Federal é alçado à posição central no campo da política, deslocando para posição secundária o Governo Municipal, responsável pela fiscalização do cumprimento das condicionalidades e pela "punição" dos que ferem as condicionalidades; 4) esses programas produzem os "coletivos de destino" que são, ao mesmo tempo, "coletivos de votantes", marcados pela precariedade, o medo e a insegurança; 5) o "beneficiário" do PBF produz uma inversão no campo da política com relação aos sentidos de proximidade e distância, onde o geograficamente distante é o próximo e vice-versa; 
6) o campo da política é constituído, essencialmente, de duas escalas: municipal e federal; a estadual é quase invisível; 7) a proximidade (na distância) é permeada pela confiança e o distanciamento (na proximidade) é permeado pelo medo; 8) o território da política - como novo sistema de tramas se alarga e é permeado por novas funcionalidades e contradições, tensões e conflitos;

No âmbito social: 1) como nos campos econômico e político, a realidade social (sistemas de produção de objetos, de representações e de ações sociais) do Território vem sendo profundamente abalada; 2) na escala das rotinas domésticas, essas mudanças são visíveis nas casas, nos trajetos diários dos moradores (a questão da água), nas atividades que realizam (em casa, na roça, na escola...); 3) na escala das rotinas difusas, com o ingresso da luz elétrica, da televisão, do dinheiro da economia pública, com as condicionalidades do PBF e em virtude da rarefação de habitantes, é desmanchada ou refeita a rede de vizinhança e a própria comunidade local (associação, dinheiro); 4) o dinheiro do PBF e as condicionalidades contribuem para o alongamento ou complexificação dos trajetos e para o alargamento de redes de sociabilidade e de territórios de todos os membros da casa; 5) a subordinação ao dinheiro da economia pública e às suas contingências introduz alterações nas escalas das relações sociais; produz, também, novos campos ou lugares de tensões (homem e mulher, pais e filhos, compradores e vendedores de diárias, agentes públicos e beneficiários...); 6) os sistemas de sociabilidade e territorialidade ganham novos contornos, alargam-se ou estreitam-se, envolvem novas situações de distanciamento ou aproximação.

Em síntese, nesse novo contexto, a vida rotina do "homem simples" do TIBJ se esboça, localiza e escorre exatamente como um espaço-tempo tenso, meio híbrido, invadindo o conjunto dos sistemas de objetos, de representações e de ações sociais. $\mathrm{O}$ agricultor familiar é cada vez mais transformado em consumidor do sistema, distanciado da sua produção e conduzido por um dinheiro da economia pública; ele é envolvido por uma complexa rede de abordagens que o tornam crescentemente precário, dependente nos âmbitos econômico, político e social. Precarizado e medroso, medroso porque precarizado. Produz-se, de modo sutil, mas denso, um novo processo de destruição de dignidade, em nome da sua inclusão nos sistemas e nas redes econômica, política e social de consumo. Ele é consumido pela economia pública para a segurança da política.

(Recebido para publicação em 26 de outubro de 2010) (Aceito em 10 de maio de 2011)

\section{REFERÊNCIAS}

ACSELRAD, Henri. Território, localismo e política de escalas. In: ACSELRAD, Henri et al. Cidade, ambiente e política. Problematizando a agenda 21 local. Rio de Janeiro: Garamond, 2006

BRASIL. Ministério da Previdência. Estatísticas Municipais 2000-2010. Disponível em: www. previdencia.gov.br/ conteudoDinamico.php?id $=484$.

DAVEZIES, Laurent. La république et ses territoires: la circulation invisible des richesses. Paris: Seuil, 2008

FAVERO, Celso Antonio. Bengalas e campos de tensões: as organizações camponesas na Bahia. 1991. Dissertação (Mestrado) - Universidade Federal da Bahia.Salvador: 1991.

GIDDENS, Anthony. As consequências da modernidade. São Paulo: Ed. UNESP, 1991.

A constituição da sociedade. São Paulo: Martins Fontes, 2003

HARVEY, David. A produção capitalista do espaço. São Paulo: Annablume, 2006.

IANNI, Octavio. A mentalidade do homem simples. In: IANNI, Octavio. Sociologia e sociedade no Brasil. São Paulo: Ed. Alfa-Omega, 1975.

IVO, Anete Brito Leal. Viver por um fio. Pobreza e política social. São Paulo: Annablume; Salvador: CRH/UFBA, 2008

JOBERT, Bruno. Estado, sociedad, políticas públicas. Santiago,Chile: LOM Ediciones, 2004.

MARTINS, José de Souza. A sociabilidade do homem simples: modernidade e história na modernidade anômala. 2.ed. São Paulo: Contexto, 2008.

\section{Vozes, 1981.}

Os camponeses e a política no Brasil. Petrópolis:

MARX, Karl. Elementos fundamentales para la crítica de la economía política - Grundrisse 1857-1858. 14.ed. México: Siglo Veintiuno Editores, 1986.

MOC. Plano de safra territorial do Conselho Regional de Desenvolvimento Rural Sustentável da Bacia do Jacuípe do Estado da Bahia produzido em parceria com a Secretaria de Desenvolvimento Territorial do Ministério do Desenvolvimento Agrário. 2007. Disponível em: http://servsdt-1.mda.gov.br/sit/ bibliotecavirtual/pst/ pst_territorio014.pdf.

SABOURIN, Eric. Ação coletiva e organização dos agricultores no Nordeste semiárido. In: CONGRESSO DA 
SOBER,37,ago.1999, Foz de Iguaçu,PR.

. Camponeses no Brasil. Entre a troca mercantil e a reciprocidade. Rio de Janeiro: Garamond, 2009.

SANDI, Ricardo Dinarte; HERINGER, Luiz Pérsio. A Previdência Social nos municípios do Semiárido brasileiro. Informe de Previdência Social, Brasíliia, v.13, n.8, ago., 2001

SANTOS, Milton; SILVEIRA, Maria Laura. O Brasil: território e sociedade no inicio do século XXI. Rio de Janeiro: Record, 2001.

. O dinheiro e o território. Geografia, São Paulo, v.1, n.1, p.8-9, jan./jun., 1999.
SEI. Superintendência de Estudos Econômicos e Sociais da Bahia. Evolução e caracterização das manchas de pobreza na Bahia (1991-2000). Salvador: 2008. (Série estudos e pesquisas,79).

SPE/SEPLANTEC. A espacialização do desenvolvimento social no território baiano. Salvador, 2001. (Série políticas públicas, 2)

TENDLER, Judith. New lessons from old projects: the workings of rural development in Northeast Brazil. Washington: D.C: The World Bank, 1993.

VEIGA, José Eli da. A dimensão rural do Brasil: programa de seminários acadêmicos. $5^{\mathrm{a}}$ feira. São Paulo: FEA-USP. Seminário $n^{\circ}$ 4/2004. Disponível em: www.econ.fea.usp.br/ seminarios/artigos/ dimensao rural.pdf. 


\section{PUBLIC POLICIES AND RESTRUCTURING OF NETWORKS OF SOCIABILITIY IN FAMILY FARMING}

\author{
Celso Antonio Favero
}

The objective of the researches that originated this paper is to acknowledge displacement created in the lives and routines of the family farmer of semiarid region of the North-east of Brazil with the introduction of the policies of conditional income transference. The money of this policies added to the money from other transferences, are they appropriate, are they used and represented upon the families of those farmers? To answer this question let's begin from four ideas: 1) nowadays the territorialization of capital tend to balance itself out in the combination of territories that produce wealth and territories of transference of income; 2) the introduction of the money from public transferences promotes displacement in relation to positions and availability of individuals in their families as well as the families in their local sociability networks; 3)in the new policies for family farming in semi-arid region, runs the idea development for consumption; 4) the State has become main player in the production of those displacement.

KEY WORLDS: territories, semi-arid, family farming, public policies.

\section{POLITIQUES PUBLIQUES ET RESTRUCTURATION DES RÉSEAUX DE SOCIABILITÉS DANS L'AGRICULTURE FAMILIALE}

\author{
Celso Antonio Favero
}

Les recherches qui sont à l'origine de ce travail ont pour objectif de connaître les changements qui ont eu lieu dans la vie et la routine des agriculteurs de la région semi-aride du Nord-est du Brésil, à cause de l'introduction des politiques de "transfert conditionné de revenus". Comment les fonds relatifs à ces politiques, ajoutés à d'autres fonds, sont-ils adaptés, utilisés. Que représentent-ils pour les familles de ces agriculteurs? Pour répondre à ces questions, on part de quatre principes: 1) actuellement la territorialisation du capital tend à rechercher son équilibre dans une combinaison entre territoires de production de richesses et territoires de transfert de revenus; 2) l'entrée d'argent des fonds publics provoque des changements dans la position et la place des individus dans les familles, mais aussi des familles par rapport aux réseaux locaux de sociabilité; 3) les nouvelles politiques pour l'agriculture familiale de la région semi-aride suscite une idée de développement pour la consommation; 4) l'État est devenu le protagoniste essentiel de ces changements.

MOTS-CLÉS: territoire, semi-aride, agriculture familiale, politiques publiques.

Celso Antonio Favero - Doutor em Sociologia pela Université du Québec, Montréal (UQAM). Professor do Departamento de Ciências Humanas e do Programa de Pós-Graduação em Políticas Públicas, Gestão do Conhecimento e Desenvolvimento Regional no Campus I da Universidade do Estado da Bahia (UNEB). Coordenador do Grupo de Estudos e Pesquisas "Territórios, Hegemonias, Periferias e Ausências" e membro da Coordenação do "Núcleo de Cooperação e Ações em Políticas Públicas e Economia Solidária" (COAPPES). Avaliador Institucional e de Cursos pelo INEP. Linhas de pesquisa: Sociologia Rural, Planejamento (territorial, municipal, institucional), Movimentos Sociais e Políticas Públicas. Últimas publicações: Sociabilidades, trajetos e desencaixes: bolsa família e agricultores familiares no semiárido baiano. CyCL de la ALAS, v. n. 4, p. 73-109, 2011; Produção de riquezas, atratividade e bolsa família a agricultura familiar no semiárido brasileiro. Tempo da Ciência (UNIOESTE), v. 17, p. 9-39, 2010. 